\title{
O que o crack tem a ver com a rua? Uma revisão narrativa com implicaçóes políticas (2011-2017)
}

\section{| ${ }^{1}$ Dayana Rosa Duarte Morais, ${ }^{2}$ Martinho Braga Batista e Silva |}

Resumo: Objeto: Produção científica sobre o crack e a rua publicada em periódicos brasileiros indexados no SciELO e portal CAPES. Objetivo: Revisar tal produção, trabalhando os resultados a fim de investigar a recente associação entre pessoas que fazem uso de crack e que se encontram em situação de rua. Metodologia: Busca na base online de artigos do SciELO e portal CAPES, utilizandose 3 out. 2017 como corte temporal, "crack AND rua", "crack AND moradores de rua" e "crack AND população em situação de rua" como "termo pesquisado" a partir de 2011 a outubro de 2017. Identificaram-se 63 referências, cujos resumos foram analisados, chegando-se aos 20 artigos que, efetivamente, dizem respeito à questão da associação entre crack e rua. Análise: critérios institucionais (título, periódico e data de publicação). Categorias: "crack e população em situação de rua"; "crack e o espaço da rua" e “indexadores históricos das ruas". Resultados: Dentre os 20 artigos consultados, 18 vinculam diretamente o consumo de crack à população em situação de rua e/ou ao espaço da rua. A associação entre crack e rua é notável não só na produção científica nacional sobre o consumo da "droga", mas também na produção normativa e governamental.

> Palavras-chave: crack; rua; políticas públicas.

\author{
${ }^{1}$ Instituto de Medicina Social, \\ Universidade do Estado do Rio de \\ Janeiro. Rio de Janeiro-RJ, Brasil \\ (dayanarosa@id.uff.br). \\ ORCID: 0000-0003-0666-6834 \\ 2 Instituto de Medicina Social, \\ Universidade do Estado do Rio de \\ Janeiro. Rio de Janeiro-RJ, Brasil \\ (silmartinho@gmail.com). \\ ORCID: 0000-0003-3577-958X
}

Recebido em: 03/07/2019 Aprovado em: 25/03/2020 Revisado em: 30/05/2020 


\section{Introdução}

O tema das ruas, dos moradores de rua, da situaçáo de rua, é hoje ao mesmo tempo gerador de debates e produzido por uma reflexão específica sobre as "drogas", um dispositivo das drogas que parece oferecer hoje o guarda-chuva para se pensar qualquer questáo vinculada às ruas. "É morador de rua ou usuário de crack?" - eis a aporia que precariza a situação de rua, por um lado; que a criminaliza, por outro. As drogas, e sobretudo o crack, se tornaram, no Brasil contemporâneo, um debate que parte das ruas para tomar o espaço público, debate a um só tempo moral e político, de mercado e religioso (RUI; MARTINEZ; FELTRAN, p. 15, grifos nossos).

Com o objetivo de compreender como uma parcela da produção científica nacional aborda o consumo de crack, conduzimos uma revisão narrativa de artigos publicados durante sete anos, além de outras publicaçôes complementares. Partimos da hipótese de que especialistas vinculam o consumo de crack cada vez mais ao contexto da rua. Além disso, sustentamos que esse processo de naturalização da relação entre crack e rua tem implicações não só de ordem científica, como também política.

Partilhamos do ponto de vista segundo o qual o conceito "droga" tem um significado plural e não único, consolidando-se no imaginário como substância ilícita apenas no século XX. No século XIV era sinônimo de especiaria (como pimenta, cravo e outros). Já foi vista como alimento (chá e café, por exemplo), e também fármaco. As fronteiras entre drogas, medicamentos, alimentos e condimentos, nítidas no início do século XXI, são efeito de uma partilha moral (VARGAS, 2008). Assim, “[...] de um modo geral, o vocábulo 'droga' designa, em diferentes línguas, ora substâncias materiais, ora juizos de valor, quando não os designa simultaneamente" (VARGAS, 2001, p. 73, grifo nosso), e esteve estreitamente ligado ao prazer no passado - a busca do sabor do paraíso, das especiarias - e apenas muito recentemente passou a ser associado exclusivamente ao dano - o efeito dito nocivo do abuso de substâncias psicoativas, como o próprio crack (VARGAS, 2001).

A associação entre drogas e espaços, no entanto, sejam eles públicos ou privados, não surge com o crack. Schivelbusch (1993) nos lança em direção a uma apreensão histórica de alguns produtos que costumamos consumir na sociedade contemporânea, tais como café e cerveja. Esta era valorizada por suas propriedades nutritivas, que ao longo do tempo foram minimizadas em relação àquelas de desinibição, fazendo da bebida um elemento central nos bares e tavernas; já o café, pouco presente no cotidiano europeu até o século XVII, ganhou o estatuto de bebida 
da sobriedade, ordenando em torno de si uma movimentada produção literária nos estabelecimentos batizados com o nome da infusão, e tornando-se onipresente em repartiçôes públicas: "in the nineteenth century the tavern was as important a place for the working class as the seventeenth-and eighteenth-century coffeehouse had been for the middle class" (SCHIVELBUSCH, 1993, p. 166).

Outras relações entre substâncias e espaços foram apontadas por Mintz (1986) em seu estudo sobre os usos e sentidos do açúcar, que viria a substituir o mel como principal adoçante em consumo no mundo. Já a sacarina, descoberta em 1879, foi utilizada como medicamento, tempero, material decorativo e conservante. O chá passou a ser consumido adoçado na corte inglesa, e posteriormente o conhecido ritual do "chá das cinco" tornou-se um costume inclusive nas casas das classes trabalhadoras, fortalecendo os "inside kinds of meaning" (MINTZ, 1986, p. 151). Finalmente, a própria proibição do consumo de bebidas alcoólicas entre os motoristas de veículos automotores no final do século XX (GUSFIELD, 2009), e do uso de tabaco em espaços coletivos fechados no início do século XXI, também ilustram as relaçôes entre substâncias e espaços.

Nos estudos que apresentaremos a seguir, não encontraremos relaçōes unívocas entre substâncias e espaços. As pessoas em situação de rua têm sido vinculadas ora à migração, ora ao desemprego, certas vezes à exclusão social e mesmo à pobreza.

A produção científica sobre as pessoas em situação de rua na década de 1990 apresenta uma unidade: "O mote explicativo, baseado na relação migração, desemprego e rua, construiu um discurso baseado na questão das 'perdas, carência e falta' para essa população, marcando as pesquisas e políticas públicas do período” (OLIVEIRA, 2012, p. 25, grifo nosso). Esse autor apresenta como os "moradores de rua" do interior de São Paulo têm sido produzidos e gerenciados, sinalizando duas pesquisas realizadas no momento em que os "personagens" do centro da cidade passam a ser percebidos como não representantes legítimos do processo de mudança que se colocava enquanto projeto político para a nação: Stoffels (1977), em sua investigação em São Paulo, situa a "mendicância" a partir das formas de reproduçáo social da classe trabalhadora; já Neves (1983), que pesquisa no Rio de Janeiro, tipifica o grupo como ex-trabalhadores, filhos de trabalhadores e migrantes.

O estudo de Escorel (1999) está inserido no campo do debate sobre a pobreza urbana, procurando expor os condicionantes macroestruturais que se configuraram no Brasil, especificamente na capital fluminense, ao longo da década de 1980. 
Através das trajetórias de vida anteriores à "situação de rua", a autora elenca categorias para a observação da "exclusão social" no cotidiano dos "moradores de rua", caracterizando-a como algo distinto de privação material: "a exclusão social significa, então, o não encontrar nenhum lugar social, o não pertencimento a nenhum topos social, uma existência limitada a sobrevivência singular diária" (ESCOREL, 1999, p. 81, grifos nossos). Já o estudo de De Lucca (2007), em São Paulo, mostra como a Teologia da Libertaçáo concebia o dito "povo da rua" e em que medida a intervenção das pastorais favoreceu a emergência do Movimento Nacional da População de Rua: "Entre a massa indiferenciada e indiscernível de uma pobreza sem casa, sem trabalho e sem referências, foi sendo destacada a parcela daqueles que hoje são identificados, classificados e codificados como população de rua" (DE LUCCA, 2007, p. 33, grifo nosso).

Como Escorel (1999), Silva Filho (2007) também não considera a situação de rua sinônimo de privação material, no sentido de renda diminuída ou inexistente, nem mesmo de desemprego, já que nela vigora o trabalho informal, sublinhando a permanência de uma "intensa comunicação entre a vida da cidade e a economia da miséria existente entre populaçôes de rua” (SILVA FILHO, 2007, p. 3). O autor questiona vários mitos, como o da marginalidade, da exclusão e do êxodo rural, como vetores da situação de rua na metrópole carioca, associando-a a uma desigualdade da pobreza que se dá pela diversidade de usos de recursos escassos: "A moradia é uma entre as diversas possibilidades de uso da rua. É para isso que a rua 'serve': ampliar o acesso a recursos escassos pelo isolamento geográfico da pobreza" (SILVA FILHO, 2007, p. 22, grifo nosso).

Desta maneira, relaçóes entre substâncias e espaços foram sinalizadas em diferentes estudos sociológicos e históricos, mas nunca crack e rua (até porque o fenômeno do consumo do crack só emerge recentemente, no final do século XX); ao mesmo tempo, as pessoas em situação de rua foram associadas a vários fenômenos, como migração, desemprego, exclusão social e pobreza, nenhum deles o consumo de crack. Entretanto, no excerto que inicia este artigo, a associação entre crack e rua foi apontada (RUI; MARTINEZ; FELTRAN, 2016), seja pela relação entre substância e espaço, seja pelo vínculo entre usuários e populaçôes.

Enquanto eram divulgadas informaçôes acerca das "cracolândias" e disseminavase a ideia de que estaríamos vivendo uma "epidemia do crack" no Brasil dos anos 2000, um conjunto de políticas de "combate ao crack" foi formulado. Em matéria 
do jornal O Globo, intitulada "Consumo de crack cresce sem controle no Brasil" e publicada em 2011, é divulgado que no Rio de Janeiro o uso da "droga" teria subido de 1 para 10\% em um ano, segundo dados do Programa de Estudos e Assistência ao Uso Indevido de Drogas (Projad/ UFRJ) - dados que dois anos depois seriam refutados pela pesquisa Perfil Nacional dos Usuários de crack elou Similares (2013). Ainda na mesma matéria foi publicado que "a prefeitura do Rio estima que pelo menos 800 pessoas em situação de risco (moradores de rua, principalmente) são viciadas em crack" (O GLOBO, 2011, grifo nosso). A Resolução no 20 da Secretaria Municipal de Assistência Social do Rio de Janeiro, promulgada no mesmo ano de 2011, cria e regulamenta o "protocolo do serviço especializado em abordagem social", tomando como público-alvo de suas açôes "pessoas em situação de rua” e espaço de intervenção "os logradouros da Cidade do Rio de Janeiro". Segundo esta resolução municipal:

A criança e o adolescente que esteja nitidamente sob a influência do uso de drogas afetando o seu desenvolvimento integral, será avaliado por uma equipe multidisciplinar e, diagnosticada a necessidade de tratamento para recuperação, o mesmo deverá ser mantido abrigado em serviço especializado de forma compulsória (RIO DE JANEIRO, 2011, p. 6, grifos nossos).

Essa normativa ficou conhecida por suscitar "açôes de recolhimento", a "internação compulsória de crianças e adolescentes em situação de rua" tendo sido associada à guerra às drogas por alguns analistas: "O estigma de 'dependente químico' e 'usuário de crack', atribuido à maioria daqueles que vivem na rua, serve de justificativa para a intervenção pública e a internação forçada" (MACERATA; DIAS; PASSOS, 2013, p. 28, grifo nosso). Seria essa resolução municipal uma expressão normativa da associação entre o consumo de crack e o contexto de rua, ou mesmo entre as pessoas em situação de rua e os usuários de crack? Em outras palavras, como questiona o título deste texto, o que o crack tem a ver com a rua?

\section{Metodologia}

Para responder a essas questôes, conduzimos uma revisão da produção científica nacional sobre o consumo de crack, tomando como marco histórico a citada normativa promulgada no ano de 2011. Diferentemente da revisão sistemática realizada por Rodrigues et al. (2012) sobre o conhecimento produzido acerca do crack, optamos por uma revisão narrativa dessa produção, tal como Toledo, Gongora e Bastos (2017) fizeram para identificar contextos de vulnerabilidade que colocam 
usuários de crack em situaçôes de exclusão social. Esta opção metodológica permite que materiais selecionados previamente sejam agregados.

Foram utilizadas a base de dados SciELO (Scientific Electronic Library Online) e o portal CAPES (Coordenação de Aperfeiçoamento de Pessoal de Nível Superior), considerando materiais publicados entre o ano de 2011 e outubro de 2017. Foram buscados os descritores "crack AND rua", "crack AND moradores de rua" e "crack AND população em situação de rua”.

A busca foi realizada seguindo os seguintes passos: (1) leitura dos resumos de todos os artigos identificados a partir dos descritores; (2) exclusão de textos em outros formatos que não de artigo, originários de outros países, artigos duplicados ou que não mantêm relação direta com o tema; (3) leitura na íntegra dos artigos restantes. Dentre os 64 artigos levantados, foram excluídos 44 com base nas etapas citadas anteriormente. Os demais 20 artigos (quadro 1), em grande parte, foram publicados em revistas da área da Saúde Coletiva, três deles de Ciências Sociais, dois de Psicologia e um de Psiquiatria.

Quadiro 1. Extraçấo de dados (03/10/2017)

\begin{tabular}{|l|l|c|l|}
\hline Título & Autor & Ano & Periódico \\
\hline $\begin{array}{l}\text { Usuários de crack em situação de } \\
\text { rua - características de gênero }\end{array}$ & $\begin{array}{l}\text { Taís Veronica Cardoso Vernaglia; } \\
\text { Regina Amélia de Magalhães } \\
\text { Senna; Marcelo Santos Cruz }\end{array}$ & 2015 & $\begin{array}{l}\text { Ciência \& Saúde } \\
\text { Coletiva }\end{array}$ \\
\hline $\begin{array}{l}\text { Crack: Uma Abordagem } \\
\text { Psicanalítica de seu Consumo } \\
\text { entre Crianças e Adolescentes em } \\
\text { Situação de Rua }\end{array}$ & $\begin{array}{l}\text { Cláudia Henschel de Lima; } \\
\text { Adilson Pimentel Valentim; } \\
\text { Carlos Emmanuel Da F. Rocha; } \\
\text { Natália Ferreira Rodrigues }\end{array}$ & 2013 & $\begin{array}{l}\text { Revista Mal Estar } \\
\text { e Subjetividades }\end{array}$ \\
\hline $\begin{array}{l}\text { Equipe "Consultório na Rua" de } \\
\text { Manguinhos, Rio de Janeiro, Brasil: } \\
\text { práticas de cuidado e promoçáo da } \\
\text { saúde em um território vulnerável }\end{array}$ & $\begin{array}{l}\text { Elyne Montenegro Engstrom; } \\
\text { Mirna Barros Teixeira }\end{array}$ & 2016 & $\begin{array}{l}\text { Ciência \& Saúde } \\
\text { Coletiva }\end{array}$ \\
\hline $\begin{array}{l}\text { Uma revisão da produção cientifica } \\
\text { brasileira sobre o crack - } \\
\text { contribuiçóes para a agenda política }\end{array}$ & $\begin{array}{l}\text { Marcelo Rasga Moreira; } \\
\text { Fernandes, Fernando Manuel } \\
\text { Thereza de Lamare Franco Neto }\end{array}$ & 2015 & $\begin{array}{l}\text { Ciência \& Saúde } \\
\text { Coletiva }\end{array}$ \\
\hline $\begin{array}{l}\text { À margem: uso de crack, desvio, } \\
\text { criminalização e exclusão social - } \\
\text { uma revisão narrativa }\end{array}$ & $\begin{array}{l}\text { Lidiane Toledo; Andrés Gongora; } \\
\text { Francisco Inácio P. M. Bastos }\end{array}$ & 2017 & $\begin{array}{l}\text { Ciência \& Saúde } \\
\text { Coletiva }\end{array}$ \\
\hline
\end{tabular}

continua... 


\begin{tabular}{|c|c|c|c|}
\hline Título & Autor & Ano & Periódico \\
\hline $\begin{array}{l}\text { Sedução e descaminho - } \\
\text { Narrativas e Identidades de Jovens } \\
\text { em situação de rua }\end{array}$ & Hugo Juliano Duarte Matias & 2013 & $\begin{array}{l}\text { Psicologia: } \\
\text { Reflexão e } \\
\text { Crítica }\end{array}$ \\
\hline $\begin{array}{l}\text { Conhecimentos produzidos } \\
\text { acerca do crack: uma incursão nas } \\
\text { dissertaçóes e teses brasileiras }\end{array}$ & $\begin{array}{l}\text { Diego Schaurich Rodrigues; } \\
\text { Dirce Stein Backes; Hilda Maria } \\
\text { Barbosa de Freitas; Claudia } \\
\text { Zamberlan; Maria Helena } \\
\text { Gelhen; Juliana Silveira Colomé }\end{array}$ & 2012 & $\begin{array}{l}\text { Ciência \& Saúde } \\
\text { Coletiva }\end{array}$ \\
\hline Abuso e dependência: crack & $\begin{array}{l}\text { Associação Brasileira de } \\
\text { Psiquiatria }\end{array}$ & 2012 & $\begin{array}{l}\text { Revista da } \\
\text { Associaçâao } \\
\text { Médica Brasileira }\end{array}$ \\
\hline $\begin{array}{l}\text { Experiências de adolescentes em } \\
\text { uso de crack e seus familiares } \\
\text { com a atenção psicossocial e } \\
\text { institucionalização }\end{array}$ & $\begin{array}{l}\text { Milena Lima de Paula; Maria } \\
\text { Salete Bessa Jorge; Leilson Lira de } \\
\text { Lima; Indara Cavalcante Bezerra. }\end{array}$ & 2017 & $\begin{array}{l}\text { Ciência \& Saúde } \\
\text { Coletiva }\end{array}$ \\
\hline $\begin{array}{l}\text { Tensôes paradigmáticas nas } \\
\text { políticas públicas sobre drogas: } \\
\text { análise da legislação brasileira no } \\
\text { período de } 2000 \text { a } 2016\end{array}$ & $\begin{array}{l}\text { Mirna Barros Teixeira; Marise de } \\
\text { Leão Ramoa; Elyne Engstron; } \\
\text { José Mendes Ribeiro }\end{array}$ & 2017 & $\begin{array}{l}\text { Ciência \& Saúde } \\
\text { Coletiva }\end{array}$ \\
\hline $\begin{array}{l}\text { Realidade sociopolítica, ambiental } \\
\text { e de saúde de famílias pertencentes } \\
\text { a uma comunidade vulnerável }\end{array}$ & $\begin{array}{l}\text { Carla Kowalski Marzari; Dirce } \\
\text { Stein Backes; Marli Stein Backes; } \\
\text { Mara Teixeira Marchiori; Martha } \\
\text { Teixeira de Souza; Adriana } \\
\text { Dornelles Carpes }\end{array}$ & 2013 & $\begin{array}{l}\text { Ciência \& Saúde } \\
\text { Coletiva }\end{array}$ \\
\hline $\begin{array}{l}\text { Corpo-afeto, corpo-violência: } \\
\text { experiências na prostituição de } \\
\text { estrada na Paraíba }\end{array}$ & Silvana de Souza Nascimento & 2014 & Ártemis \\
\hline $\begin{array}{l}\text { Ação social de pentecostais e da } \\
\text { renovação carismática católica no } \\
\text { brasil. O discurso de seus líderes }\end{array}$ & Cecília Loreto Mariz & 2016 & $\begin{array}{l}\text { Revista Brasileira } \\
\text { de Ciências } \\
\text { Sociais }\end{array}$ \\
\hline $\begin{array}{l}\text { Juventude violenta: processos, } \\
\text { retrocessos e novos percursos }\end{array}$ & Alba Zaluar & 2012 & Revista Dados \\
\hline $\begin{array}{l}\text { Economia moral e modelos de } \\
\text { atenção no cuidado com gestantes } \\
\text { que usam crack }\end{array}$ & $\begin{array}{l}\text { Fernanda dos Santos de Macedo; } \\
\text { Paula Sandrine Machado }\end{array}$ & 2016 & Saúde em Debate \\
\hline $\begin{array}{l}\text { A dinâmica das relaçóes } \\
\text { familiares de moradores de rua } \\
\text { usuários de crack }\end{array}$ & $\begin{array}{l}\text { Jaime Caravaca-Moreira; Maria } \\
\text { Itayra Alonso e Padilha }\end{array}$ & 2015 & Saúde em Debate \\
\hline
\end{tabular}




\begin{tabular}{|l|l|c|l|}
\hline Título & Autor & Ano & Periódico \\
\hline $\begin{array}{l}\text { Territórios psicotrópicos na região } \\
\text { central da cidade de Porto Alegre, } \\
\text { RS, Brasil }\end{array}$ & $\begin{array}{l}\text { Luciane Raupp; e Rubens de } \\
\text { Camargo Ferreira Adorno }\end{array}$ & 2015 & $\begin{array}{l}\text { Saúde e } \\
\text { Sociedade }\end{array}$ \\
\hline $\begin{array}{l}\text { Semelhanças e contrastes nos } \\
\text { padróes de uso de crack em Santa } \\
\text { Catarina, Brasil: capital vs Meio } \\
\text { Oeste }\end{array}$ & $\begin{array}{l}\text { Maria Terezinha Zeferino; Vivian } \\
\text { Costa Ferno; Marcelo Brandt } \\
\text { Fialho; Francisco Inácio Bastos }\end{array}$ & 2017 & $\begin{array}{l}\text { Ciência \& Saúde } \\
\text { Coletiva }\end{array}$ \\
\hline $\begin{array}{l}\text { Revisão sistemática da literatura } \\
\text { sobre } \text { crack: análise do seu } \\
\text { uso prejudicial nas dimensóes } \\
\text { individual e contextual }\end{array}$ & $\begin{array}{l}\text { Mirna Barros Teixeira, Elyne } \\
\text { Montenegro Engstrom, José } \\
\text { Mendes Ribeiro }\end{array}$ & 2017 & Saúde Debate \\
\hline $\begin{array}{l}\text { Vulnerabilidades clínicas e sociais } \\
\text { em usuários de } \text { crack de acordo } \\
\text { com a situaçáo de moradia: um } \\
\text { estudo multicêntrico de seis } \\
\text { capitais brasileiras }\end{array}$ & $\begin{array}{l}\text { Silvia Chwartzmann Halpern; } \\
\text { Juliana Nichterwitz Scherer; } \\
\text { Vinicius Roglio; Sibele Faller; } \\
\text { Anne Sordi;Felipe Ornell; Carla } \\
\text { Dalbosco; Flavio Pechansky; } \\
\text { Félix Kessler; Lísia von Diemen }\end{array}$ & 2017 & $\begin{array}{l}\text { Cadernos de } \\
\text { Saúde Pública }\end{array}$ \\
\hline
\end{tabular}

Fonte: os autores.

Além desses artigos, consideramos pertinente incluir nesta revisão um conjunto de estudos epidemiológicos e livros em que a relação entre drogas, populaçôes e espaços - no caso, crack e rua - foi abordada. São eles: 1) as séries históricas do Centro Brasileiro de Informaçóes sobre Drogas (CEBRID, 2003) da Universidade Federal de São Paulo (UNIFESP) de 1987 a 2003, mencionado em cinco dos 20 artigos mencionados; 2) o Perfil Nacional dos Usuários de crack e/ou similares (FIOCRUZ, 2013), tendo sido mencionado em três artigos; 3) o livro Crack e exclusão social (SOUZA, 2016); 4) o livro Nas tramas do Crack - etnografia da abjeção (2014); 5) o livro Novas faces da vida nas ruas (RUI; MARTINEZ; FELTRAN, 2016). Certamente, deixamos de fora livros de referência sobre o crack, como é o caso de Jamais fomos zumbis: contexto social e craqueiros na cidade de São Paulo (ALVES, 2017), Crack: contextos, padróes e propósitos de uso (McRAE; TAVARES; NUNEEZ, 2013) e Olhares plurais sobre o fenômeno do crack (JORGE, 2013). Entretanto, nosso intuito com o acréscimo de livros e estudos epidemiológicos sobre a relação entre crack e rua foi apenas complementar à revisão de artigos, e não esgotar a revisão sobre o tema. 
Compreendendo que investigar a associação entre crack e rua requer refletir sobre as relações entre substâncias e espaços, do mesmo modo como entre usuários e populaçôes, elegemos como categorias para análise: "crack e população em situação de rua"; "crack e o espaço da rua" e "indexadores históricos das ruas", este último para se referir às leituras que apontam migração, desemprego, pobreza e exclusão social como fenômenos relativos às pessoas em situação de rua na literatura sociológica e histórica.

\section{Resultados e Discussão}

Dentre os 20 artigos consultados, 18 vinculam diretamente o consumo de crack à população em situação de rua e/ou ao espaço da rua, sendo que nove se referem mais frequentemente à população em situação de rua e oito ao espaço da rua. No que diz respeito aos indexadores historicamente atribuídos à população em situação de rua, 10 deles produzem o mencionado vínculo, como veremos a seguir.

\section{Crack e população em situação de rua}

Halpern et al. (2017) identificaram relaçôes entre substância, seus usuários e uma população, entre o crack, seus consumidores e as pessoas em situação de rua. Segundo eles, essas relaçóes são apontadas pela literatura internacional, inclusive:

Em diferentes países, existe uma associação importante entre moradores de rua e o uso de substâncias ilícitas, bem como em doenças como HIV, hepatites e tuberculose. Neste estudo, a presença de HIV e hepatite foi significativamente maior entre usuários de crack moradores de rua (HALPERN et al., 2017, p. 8, grifo nosso).

Segundo os autores, no consumo de crack por pessoas em situação de rua prevalece um uso medicinal, como anestésico: "o uso de drogas é visto como uma condição intrínseca para suportar a situação de rua”(HALPERN et al., 2017, p. 8, grifo nosso).

Líderes pentecostais e da Renovação Carismática Católica entrevistados por Mariz (2016) apontam que as "drogas" são o principal problema da população de rua, sendo a dependência química causa e consequência da situação de rua:

O principal problema da maior parte dos moradores de rua seria o consumo de álcool e drogas. Argumenta-se que muitos se tornaram "sem-teto" por causa do consumo excessivo dessas substâncias e os que foram para rua por outros motivos se tornaram dependentes devido à própria experiência de vida na rua. Além do mais, a dependência química seria um grande empecilho para sair da situação de rua (MARIZ, 2016, p. 8, grifo nosso). 
Segundo estes e outros autores, a situação de rua facilitaria o consumo de crack e vice-versa, já que Henschel de Lima et al. (2013) identificam o uso de crack como um dos problemas decorrentes da situação de rua, associando população e substância, e Zeferino et al. (2017) afirmam que "estar em situação de rua tem se mostrado como fator importante na motivação do consumo da droga" (ZEFERINO et al., 2017, p. 99, grifo nosso). Estes últimos chegam a supor, com base na aparência, quais pessoas em situação de rua seriam consumidores de crack: "na maioria das cenas da capital os usuários aparentavam ser pessoas em situação de rua, com vestes sujas e rasgadas, higiene precária e problemas aparentes na pele" (ZEFERINO et al., 2017, p. 100, grifo nosso); "um contraponto importante percebido nas cenas públicas abertas de Florianópolis, diferentemente das cidades estudadas na região de Meio-Oeste, foi o predomínio de usuários de crack que apresentavam características de pessoas em situação de rua" (ZEFERINO et al., 2017, p.103, grifo nosso).

Raupp e Adorno (2015) fazem referência a ampliação da estigmatização intrínseca à associação entre crack e situação de rua: "Opera no sentido de reforçar representaçôes estigmatizantes e piorar condiçôes de socialização de grupos historicamente presentes nesses espaços, como moradores de rua, pedintes e profissionais do sexo, que acabam com suas imagens ligadas às de usuários de crack" (RAUPP; ADORNO, 2015, p. 804, grifos nossos). No mesmo sentido vão Teixeira, Engstrom e Ribeiro (2017), ao afirmar que "o estigma envolvendo o uso de crack é bem maior que com outras drogas, devido a algumas características, como: morar na rua, usar a droga em grandes conglomerados de pessoas, estar muitas vezes sujo, com imagem associada a de um 'zumbi'" (TEIXEIRA; ENGSTROM; RIBEIRO, 2017, p. 323).

Engstrom e Teixeira (2016) e Teixeira et al. (2017) identificam a Redução de Danos como a estratégia apropriada para abordar pessoas em situação de rua, o que de certo modo supóe alguma relação entre o contexto de rua e o consumo de "drogas", particularmente o crack. As autoras destacam os Consultórios na Rua como serviços especializados para o cuidado a essa população: "Dentro dessa lógica de cuidado, a atenção às pessoas em situação de rua e usuários de álcool, crack e outras drogas tem como objetivo náo apenas o controle sobre sua sintomatologia, mas o exercício pleno de sua cidadania" (ENGSTROM; TEIXEIRA, 2016, p. 1.846, grifos nossos). 


\section{Crack e o espaço da rua}

Compreender o contexto da rua como facilitador do consumo de crack aponta para a contribuição das séries históricas do CEBRID (2003) que, até 1997, realizava a coleta de dados apenas em instituiçóes com sedes (escolas, domicílios, etc.) condição esta que favorecia a composição da amostra de crianças e adolescentes a serem entrevistados. No entanto, em 2003, foram localizadas várias instituiçôes que trabalhavam exclusivamente com abordagens diretas na rua, sendo que em algumas capitais esse era o único perfil de instituiçóes mapeadas. Houve, assim, a necessidade de buscar alternativas para a adaptação da metodologia em campo aberto (rua), especialmente para o processo de amostragem: "o consumo de drogas entre essa população pode ser encarado como um comportamento que denuncia as condiçôes que favorecem a situação de rua" (CEBRID, 2003, p. 31, grifo nosso).

Atualizando ainda mais a abordagem metodológica para pesquisas sobre população em situação de rua e uso de "drogas", o Perfil Nacional de Usuários de Crack e/ou Similares (FIOCRUZ, 2013) adotou o método NSUM (Network Scale-up Method), que consegue contabilizar populaçóes de difícil acesso como as populaçôes que vivem nas ruas ou em abrigos, por exemplo. Nessa metodologia, não importa se o usuário está em sua residência ou não, ou seja, a percepção de um novo conjunto de atores de pesquisa demandou uma reformulação no próprio modo de produção de conhecimento.

A trajetória pessoal da autora de Nas tramas do crack (2014) nos provoca a pensar a relação entre substâncias e espaços, pois ela refere sua experiência como educadora social de rua como ponto de partida para sua investigação sobre consumo de crack: "considero que tanto o fato de ter trabalhado como educadora de rua quanto as pesquisas acadêmicas que fiz em torno de temas convergentes acumularam-se e me garantiram certa destreza para circular pelos espaços observados nesta pesquisa" (RUI, 2014, p. 57). Em suma, a autora trabalha com a dupla via: "o crack pode tanto ser uma possibilidade para quem já frequentava as ruas quanto pode levar indivíduos a essa condição" (p. 295). Ou seja, se antes os estudos epidemiológicos apontavam a rua como um contexto social favorável ao uso do crack, se alguns daqueles do campo da Saúde Coletiva aproximavam as propriedades químicas desta substância ao estilo de vida dessa população, agora temos também que tal substância pode encaminhar seus usuários a essa situação. 
Hugo Matias (2012), analisando narrativa e identidades de jovens que vivem nas ruas de Natal-RN, destacou dentre suas entrevistas a seguinte fala: "desde o momento que foi para rua, então conheceu a maconha, depois o crack, limpa parabrisas de carros e está onde está" (MATIAS, 2012, p. 548, grifo nosso). A rua condicionadora do uso também foi percebida na revisão realizada por Moreira et al. (2015), segundo a qual "a presença, na 'cracolândia', de crianças que vivem nas ruas é influenciada pelos 'círculos de sociabilidade e socialização' que estas vivenciam e que lhes colocam em contato direto com o uso de drogas" (MOREIRA et al., 2015, p. 1.054, grifo nosso).

Toledo, Gongora e Bastos (2017, p. 34, grifo nosso) partem do conceito de cena aberta de uso e o caracterizam, em parte, como um lugar ermo que "colabora para a prática de atos ilícitos/ estigmatizados, como a prostituição, os furtos e roubos, $o$ tráfico e o uso de drogas". Ao mesmo tempo, os autores enxergam as intervenções de internação compulsória como procedimentos que se "contrapunham às motivaçôes em funções das quais os usuários passaram a utilizar a rua como espaço de referência e de estabelecimento de vínculos (inclusive com as equipes de saúde) ” (p. 38).

Segundo Rodrigues et al. (2012, p. 1.254, grifo nosso), "o consumo de crack representa uma forma de viver no cotidiano da rua". Lima de Paula et al. (2017, p. 2.738, grifo nosso) se depararam com narrativas de usuários que buscavam a institucionalização como forma de deixar as ruas: "vem um amigo me chamar pra passear, porque no meio da rua a gente só encontra o que não presta [...] A primeira coisa que eu procurei foi o Conselho (Conselho Tutelar) para buscar internação". O consumo de crack na rua também impediria a ação de políticas públicas, como é o caso em uma comunidade vulnerável: "Na fala de uma das usuárias ficou evidente que a única área verde que existe nessa região é, atualmente, utilizada pelos adolescentes para cheirar crack a noite. Logo, inexistem políticas públicas, até o momento, comprometidas com a melhoria das condiçôes ambientais" (MAZARI et al., 2013, p. 81, grifo nosso).

Segundo a produção científica nacional revisada, outro efeito do crack, agora associado às estradas do litoral norte da Paraíba, seria a diminuição do valor do programa sexual: "locais que mesclam oferta de serviços sexuais, consumo e venda de crack. Visivelmente, nos locais onde há consumo de crack, os preços dos programas são mais baratos, os locais mais sujos, e as meninas mais ariscas e provocativas" (NASCIMENTO, 2014, p. 77, grifo nosso). 


\section{Indexadores históricos das ruas}

Henschel de Lima et al. (2013), Caravaca-Moreira, Alonso e Padilha (2015) e Lima de Paula et al. (2017) notaram que, dentre as causas e consequências da associação entre crack, é frequente a referência ao núcleo familiar: "antes de experenciarem a rua, esses adolescentes já se encontram em contextos sociofamiliares marcados pela exclusão, abandono, violência física ou moral, trabalho infantil, rejeição da família, abuso de substâncias e tráfico de drogas, o que os conduz a rupturas com o núcleo familiar e comunitário" (LIMA DE PAULA et al., 2017, p. 2.738, grifo nosso).

Percebemos uma ampla utilizaçáo do conceito de vulnerabilidade no contexto da rua e consumo de crack, que no artigo de Vernaglia, Senna e Cruz (2015, p. 1.856) está sutilmente expresso ao comentar que "mulheres [usuárias de crack e em situação de rua] 'vítimas' de seus companheiros não são capazes de exprimir a complexidade que os arranjos relacionais adquirem quando se trata de lidar com adversidades extremas, caso das pessoas que vivem em situação de rua”. Corroborando Halpern et al. (2017, 9, grifo nosso), argumentam que "o grau de exclusão social de usuários de crack que, em algum momento, estiveram expostos à situação de falta de moradia e gravidade do uso, deixa-os ainda mais vulneráveis a possiveis situaçôes de violência". Nessa vulnerabilidade estariam inter-relacionados outros aspectos, como a marginalidade, o desvio e a exclusão social (TOLEDO; GONGORA; BASTOS, 2017).

Exemplo disso é o artigo da Associação Brasileira de Psiquiatria, que identificou que "prevalência do início do consumo de crack, especialmente em situaçóes com jovens em festas, grupos sociais marginalizados, sem moradia e prostitutas, pacientes dependentes de opiáceos e/ou cocaína” (ABP, 2012, p. 143, grifo nosso). O próprio conceito de "territórios psicotrópicos" (2015) traz pistas sobre essas inter-relações, uma vez que "um território psicotrópico é um local em que se desenvolvem práticas ligadas à venda e uso de drogas, estando espacial e socialmente à margem da cidade normatizada e comumente ligado a lugares de exclusão social, sendo alvo frequente de repressão policial e de estigmatização social" (RAUPP; ADORNO, 2015, p. 805 , grifos nossos).

Nesse sentido, chamamos atenção para o indexador da exclusão social, uma vez que atendendo solicitação da Secretaria Nacional de Políticas sobre Drogas (SENAD), Souza (2016) organizou o livro Crack e exclusão social, no qual é evidente a associação que se faz à droga. Nas palavras de Garcia, na época diretor de articulação e projetos da SENAD, "foram os marcadores de exclusão social que mais chamaram a 
atenção do governo federal na interpretação dessa pesquisa [...]. Somavam-se a esses, outros indicadores de vulnerabilidade social, como viver em situação de rua (40\%)" (SOUZA, 2016, p. 13, grifo nosso). "O crack e a rua” intitula o capítulo desse livro escrito por Mayora (2016), que se refere aos consumidores de crack em situação de rua enquanto "os mais pobres entre os mais pobres" ou "a ralé da ralé", o que requer uma interpretação classista ao seu ver:

O consumo de crack é a prática tóxica correspondente à precariedade das vidas secas da "ralé da ralé”. As únicas atividades que estáo disponíveis para os retirantes urbanos são aquelas extremamente desqualificadas, que exigem enorme dispêndio de energia e não garantem a mínima certeza quanto ao próximo prato de comida. O crack parece se moldar ao cotidiano da caminhada, em busca do lixo reciclável, de sobras, de lata, que ao mesmo tempo pode ser o ganha pão e o instrumento para o consumo (MAYORA, 2016, p. 149, grifo nosso).

Metade dos indexadores históricos apontados nas pesquisas sobre pessoas em situação de rua se fizeram presentes na produção científica nacional sobre o consumo de crack: exclusão social e pobreza. Além disso, como mostraram Zaluar (2012) e Macedo e Machado (2016), é possível realizar pesquisas sem relacionar este espaço/ população e esta substância especificamente. Trata-se, portanto, de uma opção, de um olhar, dentre tantos praticáveis.

\section{Considerações finais}

Segundo publicação do Instituto de Pesquisa Econômica Aplicada (2015), em tópico sobre a Assistência Social e não sobre a Saúde, há um esforço por parte do Ministério de Desenvolvimento Social no sentido de engajar seus gestores e equipes no fortalecimento das políticas de atenção à população em situação de rua, sendo que um programa relativo ao consumo de crack é citado neste mesmo relatório como relevante para a ampliação de serviços voltados para esta população: "Outro fator importante que continua contribuindo para a ampliaçáo desse serviço foi o aporte de recursos adicionados originados do programa Crack, é possível vencer que, desde 2012, contribui para a expansão desse serviço" (IPEA, 2015, p. 82). Ou seja, a associação entre o consumo de crack e a população em situação de rua não é notável apenas na produçáo científica nacional sobre o consumo de crack, como apontamos anteriormente, mas também na produção normativa e inclusive governamental.

As questôes colocadas inicialmente, sobre a associação entre crack e rua, foram abordadas ao longo do texto na forma de citaçóes de artigos, livros e estudos 
epidemiológicos variados, principalmente da área da Saúde Coletiva, mas também da Psicologia e das Ciências Sociais. Nota-se que, para muitos autores, os consumidores de crack também são potencialmente pessoas em situação de rua, e para alguns até mesmo a aparência denunciaria tais consumidores. Certos especialistas chegaram a deslocar propostas de intervenção voltadas para o cuidado a pessoas que abusam das drogas na direçấo das pessoas em situação de rua, como se usuários de drogas e população de rua coincidissem, sem falar naqueles que consideram o espaço da rua propício para o consumo de crack.

Não foi nossa intenção questionar a base dos conhecimentos científicos produzidos por esses especialistas, mas denunciar a naturalização em curso: sendo consumidor de crack, provavelmente encontra-se em situação de rua. Além disso, não é nosso objetivo conferir a veracidade dos dados científicos apresentados pelos autores citados, apenas indicar em que medida os caminhos poderiam ser outros, ou seja: poderíamos investigar também porque as pessoas em situação de rua não são mais observadas com base em fenômenos como migração e desemprego, embora sigam sendo relacionadas à pobreza e à exclusão social.

Por fim, esta revisão narrativa de uma parcela da produção cientifica nacional sobre o consumo de crack não tem apenas implicaçôes científicas, já que sublinhamos o papel desses especialistas no processo de consolidação de uma política pública que pode potencialmente confundir pessoas em situação de rua com usuários de crack, ainda que não tenham como finalidade a internação compulsória dos mesmos. ${ }^{1}$

\section{Referências}

ALVES, Y. D. D. Jamais fomos zumbis: contexto social e craqueiros na cidade de São Paulo. Salvador: EdUFBA: Cetad: 2017. 350p.

ASSOCIAÇÃO BRASILEIRA DA PSIQUIATRIA. Abuso e dependência: crack. Revista da Associação Médica Brasileira, v. 58, n. 2, p. 141-153, 2012. Disponível em: http://www.scielo.br/ $\mathrm{pdf} / \mathrm{ramb} / \mathrm{v} 58 \mathrm{n} 2 / \mathrm{v} 58 \mathrm{n} 2 \mathrm{a} 08 . \mathrm{pdf}$

CARAVACA-MOREIRA, J.; ALONSO E PADILHA M. I. A dinâmica das relaçóes familiares de moradores de rua usuários de crack. Revista Saúde Debate, v. 39, n. 106, p. 748-759, 2015. Disponível em: http://www.scielo.br/pdf/sdeb/v39n106/0103-1104-sdeb-39-106-00748.pdf CEBRID. Levantamento Nacional sobre o Uso de Drogas entre Crianças e Adolescentes em Situação de Rua nas 27 Capitais Brasileiras. Sáo Paulo: Cebrid, 2003. 
DE LUCCA, D. Sobre o nascimento da população de rua: trajetórias de uma questão social. No prelo 2007. Disponível em: http://www.academia.edu/2711325/Sobre_o_nascimento_da_ populac\%C3\%A3o_de_rua_trajet\%C3\%B3rias_de_uma_quest\%C3\%A3o_social

ENGSTROM, E. M.; TEIXEIRA, M. B. Equipe “Consultório na Rua” de Manguinhos, Rio de Janeiro, Brasil: práticas de cuidado e promoção da saúde em um território vulnerável. Ciência e Saúde Coletiva, v. 21, n. 6, p. 1839-1848, 2016. Disponível em: http://www.scielo.br/pdf/csc/ v21n6/1413-8123-csc-21-06-1839.pdf

ESCOREL, S. Vidas ao léu: trajetória de exclusão social. Rio de Janeiro: Fiocruz, 1999.

FUNDAÇÃO OSWALDO CRUZ. Perfil dos Usuários de Crack elou Similares no Brasil- livreto domiciliar. Rio de Janeiro: Fiocruz, 2013.

GUSFIELD, J. La Culture des problèmes publics - L'alcool au volant: La production d'un ordre symbolique. Paris: Économica, 2009.

HALPERN, S. C. et al. Vulnerabilidades clínicas e sociais em usuários de crack de acordo com a situação de moradia: um estudo multicêntrico em seis capitais brasileiras. Cadernos de Saúde Pública, v. 33, n. 6, p. 1-13, 2017. Disponível em: http://www.scielo.br/pdf/csp/v33n6/16784464-csp-33-06-e00037517.pdf

HENSCHEL DE LIMA, C. et al. Crack: Uma abordagem psicanalítica de seu consumo entre crianças e adolescentes em situação de rua. Revista Mal-estar e Subjetividades, v. 8, n. 2, p. 155 194, 2013. Disponível em: http://pepsic.bvsalud.org/pdf/malestar/v13n1-2/07.pdf

INSTITUTO DE PESQUISA ECONÔMICAAPLICADA. Politicas Sociais: acompanhamento e análise. Brasília: IPEA, 2015.

JORGE, M. S. B. et al. (Orgs.). Olhares Plurais sobre o fenômeno do crack. Fortaleza: EdUECE, 2013.

LIMA DE PAULA, M. et al. Experiências de adolescentes em uso de crack e seus familiares com a atenção psicossocial e institucionalização. Ciência e Saúde Coletiva, v. 22, n. 8, p. 2735-2744, 2017. Disponível em: http://www.scielo.br/pdf/csc/v22n8/1413-8123-csc-22-08-2735.pdf

MACERATA I.; DIAS, R.; PASSOS, E. Paradigma da guerra às drogas, políticas de ordem e experiências de cuidado na cidade dos megaeventos. In BATISTA, V. M.; LOPES, L. E. (Orgs). Atendendo na Guerra (Criminologia de Cordel 3) - Dilemas médicos e jurídicos sobre o crack. Rio de Janeiro: Revan; 2013.

MARIZ, C. L. Ação social de pentecostais e da renovação carismática católica no Brasil. O discurso de seus líderes. Revista Brasileira de Ciências Sociais, v. 31, n. 92, p. 1-16, 2016. Disponível em: http://www.scielo.br/pdf/rbcsoc/v31n92/0102-6909-rbcsoc-3192042016.pdf 
MARZARI, C. K. et al. Realidade sociopolítica, ambiental e de saúde de famílias pertencentes a uma comunidade vulnerável. Ciência e Saúde Coletiva, v. 18, n. 1, p. 77-84, 2013. Disponível em: http://www.scielo.br/pdf/csc/v18n1/09.pdf

MATIAS, H. J. D. Sedução e Descaminho - Narrativas e Identidades de Jovens em situação de rua. Revista Psicologia: Reflexão e Crítica, v. 26, n. 3, p. 543-551, 2012. Disponível em: http:// www.scielo.br/pdf/prc/v26n3/v26n3a14.pdf

MAYORA, M. O crack e a rua. In: SOUZA, J. (Org.). Crack e exclusão social. Brasília: Ministério da Justiça e Cidadania, 2016.

MINTZ, S. Sweetness and Power: the place of sugar in modern history. New York: Viking Penguin, 1986.

McRAE, E.; TAVARES, L. A.; NUÑEZ, M. A (Orgs.) Crack: contextos, padrões e propósitos de uso. Salvador: EdUFBA: CETAD, 2013.

MOREIRA, M. R. et al. Uma revisão da produção científica brasileira sobre o crack contribuiçôes para a agenda política. Ciência e Saúde Coletiva, v. 20, n. 4, p. 1047-1062, 2015. Disponível em: http://www.scielo.br/pdf/csc/v20n4/pt_1413-8123-csc-20-04-01047.pdf

NASCIMENTO, S. S. Corpo-afeto, corpo-violência: experiências na prostituição de estrada na Paraíba. Revista Ártemis, v. 8, n. 1, p. 69-86, 2014. Disponível em: http://periodicos.ufpb.br/ojs/ index.php/artemis/article/view/22535/12499

NEVES, D. Mendigo: o trabalhador que não deu certo. Revista Ciência Hoje, v. 10, n. 4, p. 28-36, 1983.

O GLOBO. Consumo de crack cresce sem controle no Brasil. Disponível em: https://oglobo.globo. com/politica/consumo-de-crack-cresce-sem-controle-no-brasil-3057188. Acesso em: 17 nov. 2017. OLIVEIRA, L. M. F. Circulação e fixação: o dispositivo de gerenciamento dos moradores de rua em São Carlos e a emergência de uma população. Dissertação (Mestrado) - Universidade Federal de São Carlos, São Carlos-SP, 2012.

RAUPP, L.; ADORNO, R. C. F. Territórios psicotrópicos na região central da cidade de Porto Alegra, RS, Brasil. Revista Saúde e Sociedade, v. 24, n. 3, p. 803-815, 2015. Disponível em: http://www.scielo.br/pdf/sausoc/v24n3/0104-1290-sausoc-24-03-00803.pdf

RIO DE JANEIRO. Resolução no 20, de 27 de maio de 2011. Institui e regulamenta o recolhimento compulsório. Diário Oficial do Município do Rio de Janeiro, 2011.

RODRIGUES, D. S. et al. Conhecimentos produzidos acerca do crack: uma incursão nas dissertaçóes e teses brasileiras. Ciência e Saúde Coletiva, v. 17, n. 5, p. 1247-1258, 2012. Disponível em: http://www.scielo.br/pdf/csc/v17n5/a18v17n5.pdf

RUI, T.; MARTINEZ, M.; FELTRAN, G. (Orgs.). Novas faces da vida nas ruas. São Carlos: EdUFSCAR, 2016. 
RUI, T. C. Nas tramas do crack: etnografia da abjeção. São Paulo: Terceiro Nome, 2014.

SANTOS DE MACEDO, F.; MACHADO, P. S. Economia moral e modelos de atenção no cuidado com gestantes que usam crack. Revista Saúde Debate, v. 40, n. 109, p. 34-46, 2016. Disponível em: http://www.scielo.br/pdf/sdeb/v40n109/0103-1104-sdeb-40-109-00034.pdf

SCHIVELBUSCH, W. Tastes of Paradise: A Social History of Spices, Stimulants, and Intoxicants. New York: Vintage Books, 1993.

SILVA FILHO, D. S. Pobreza desigual entre a população de rua do Rio de Janeiro: formação de redes e critérios subjetivos de estratificação e ocupação, 2007. Disponível em: http://www. anpocs.com/index.php/papers-27-encontro-2/gt-24/gt07-9/4173-dsilvafilho-a-pobreza/file

SOUZA, J. (Org). Crack e exclusão social. Brasília: Ministério da Justiça e Cidadania, Secretaria Nacional de Política sobre Drogas, 2016.

STOFFELS, M. G. Os mendigos na cidade de São Paulo. Rio de Janeiro: Paz e Terra, 1977.

TEIXEIRA, M. B. et al. Tensões paradigmáticas nas políticas sobre drogas: análise da legislação brasileira no período de 2000 a 2016. Ciência e Saúde Coletiva, v. 22, n. 5, p. 1455-1466, 2017. Disponível em: http://www.scielo.br/pdf/csc/v22n5/1413-8123-csc-22-05-1455.pdf

TEIXEIRA, M. B.; ENGSTROM, E; RIBEIRO, J. M. Revisão sistemática da literatura sobre crack: análise do seu uso prejudicial nas dimensões individual e contextual. Saúde Debate, v. 41, n. 112, p. 311-330, 2017. Disponível em: http://www.scielo.br/pdf/sdeb/v41n112/0103-1104sdeb-41-112-0311.pdf

TOLEDO, L.; GONGORA, A.; BASTOS, F. I. À margem: uso de crack, desvio, criminalização e exclusão social - uma revisão narrativa. Ciência e Saúde Coletiva, v. 22, n. 1, p. 31-42, 2017. Disponível em: http://www.scielo.br/pdf/csc/v22n1/1413-8123-csc-22-01-0031.pdf

VARGAS, E. V. Entre a extensão e a intensidade: Corporalidade, subjetivação e uso "de drogas" [tese]. Belo Horizonte: Faculdade de Filosofia e Ciências Humanas, 2001.

. Fármacos e outros objetos sócio-técnicos: notas para uma genealogia das drogas. In: CARNEIRO, H. S. et al. (Orgs.) (Eds.). Drogas e Cultura: novas perspectivas. Salvador, BA: EDUFBA/ UFBA, 2008. p. 41-64.

VERNAGLIA, T. V. C.; SENNA, R. A. M.; CRUZ, M. S. Usuários de crack em situação de rua - características de gênero. Ciência e Saúde Coletiva, v. 20, n. 6, p. 1851-1859, 2015. Disponível em: http://www.scielo.br/pdf/csc/v20n6/1413-8123-csc-20-06-1851.pdf

ZALUAR, A. Juventude violenta: processlos, retrocessos e novos percursos. DADOS - Revista de Ciências Sociais, v. 55, n. 2, p. 327-365, 2012. Disponível em: http://www.scielo.br/pdf/ dados/v55n2/a03v55n2.pdf 
ZEFERINO, M. T. et al. Semelhanças e contrastes nos padrôes de uso de crack em Santa Catarina, Brasil: capital vs Meio Oeste. Ciência e Saúde Coletiva, v. 22, n. 1, p. 97-106, 2017. Disponível em: http://www.scielo.br/pdf/csc/v22n1/1413-8123-csc-22-01-0097.pdf

\section{Nota}

${ }^{1}$ Morais, D. R. D. trabalhou na concepção, realização da pesquisa, metodologia, discussão, resultados e redação final. Silva, M. B. B. trabalhou na concepção, metodologia, discussão, resultados e redação final. 


\section{Abstract}

What does crack have to do with the street? A narrative review with political implications (2011-2017)

Object: Scientific production on crack and street published in Brazilian journals indexed in SciELO and CAPES portal. Objective: To review such production, working on the results in order to investigate the recent association between people who use crack and who are on the street. Methodology: Search the SciELO articles online database and CAPES portal, using 3 out. 2017 as a temporal cut, "crack AND street", "crack AND homeless people" and "crack AND homeless people" as "search term" from 2011 to October 2017. We identified 63 references, whose abstracts were analyzed, arriving at the 20 articles that, effectively, concern the issue of the association between crack and street. Analysis: institutional criteria (title, periodical and date of publication). Categories: "crack and homeless people"; "Crack and street space" and "historical street indexes". Results: Among the 20 articles assessed, 18 directly linked the consumption of crack to the population living on the street and / or to the street space. The association between crack and street is notable not only in national scientific production on the consumption of "drugs", but also in normative and governmental production.

Keywords: crack; street; public policies. 